IRA-International Journal of Education \& Multidisciplinary Studies ISSN 2455-2526; Vol.05, Issue 03 (2016)

Pg. no. 203-210

Institute of Research Advances

http://research-advances.org/index.php/IJEMS

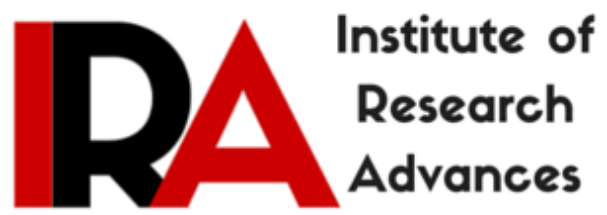

\title{
New Media English: Caught between Counter Culture, Convergence and Progress
}

\author{
Raju Chakkanattu George ${ }^{1}$ \\ Research Scholar, Bharathiar University, Coimbatore, India. \\ Dr. T. K. Pius ${ }^{2}$ \\ Associate Professor, P.G. Department of English, \\ St. Aloysius College, Elthuruth, Thrissur, India.
}

Type of Review: Peer Reviewed.

DOI: http://dx.doi.org/10.21013/jems.v5.n3.p9

\section{How to cite this paper:}

George, R., \& Pius, T. (2017). New Media English: Caught between Counter Culture, Convergence and Progress. IRA International Journal of Education and Multidisciplinary Studies (ISSN 2455-2526), 5(3), 203-210. doi:http://dx.doi.org/10.21013/jems.v5.n3.p9

(C) Institute of Research Advances

(c)) EY-NO

This work is licensed under a Creative Commons Attribution-Non Commercial 4.0 International License subject to proper citation to the publication source of the work.

Disclaimer: The scholarly papers as reviewed and published by the Institute of Research Advances (IRA) are the views and opinions of their respective authors and are not the views or opinions of the IRA. The IRA disclaims of any harm or loss caused due to the published content to any party. 


\section{ABSTRACT}

English as a language has undergone a history of transitions. These, due to historical events have contributed for the growth of the language. We are now in a world where the New Media is taking on English as a language and goes well beyond the structural patterns adding convergent symbols so that there is a global reach. The abandonment of structures like grammar, spelling and syntax enables them to converse with people who have only bare minimal knowledge of the language of English even. These are signs of counter linguistic culture and at the same time these are the convergent mantras of the Globalized world. These are also signs of the progress of the language. Here the efforts taken by the two systems of English education may not have been really used, but only in reference to them can we recognize the signs of deviation.

Key words: New Media, Language, English, Counter Culture, Convergence, Progress.

\section{Introduction}

One of the facts which separate the homo sapiens from other species is the capacity to communicate through different codified systems of symbols. These symbols, created and manipulated in tone with the cultural panorama do enable people to transfer knowledge through centuries. These systems of symbols do have the capacity to store up the treasure of knowledge for the generations to come.

Language is one of such systems which enable the storing and transferring of data through time and space. While language gives the possibility to communicate beyond such boundaries it enables us to codify the system into a consortium of systems as well and thus empowers us to create and manipulate complex knowledge (Franz 10).

In this article I intend to develop a thought pattern which asks if languages and in our case English, which is used by the social media today, do provide new questions for the English education in schools. After enlightening a little on the historical development of English as a common language I will deal with the current teaching systems of our schools in India and then move into the typical social media modus operanti of working with English thus proving a discussion forum for better clarity on the subject. At the end of the article I will draw my conclusions.

\section{History of the Development of English}

English as a language has a story of gradual developments caused by the events of history. The 'Britons' as the natives of England were called till the $5^{\text {th }}$ century, had only Celtic as their common language. In the $6^{\text {th }}$ century the Angels, Saxons and the Jutes invaded England and the Celtic was forcefully abandoned for the German language. Some preferred to abandon the home land than to abandon the language and hence there were migrations to Ireland, Scotland and Wales. Those who remained had the new language called 'Anglo-Saxon' as their new language (Rao 285-289).

In the $11^{\text {th }}$ century there was the Scandinavian invasion which contributed to the development of the vocabulary of the language. William of Normandy conquered England in 1066 and from then on the French influence did become historic for the language. If the period from 600-1100 were to be considered as the Old English period and then 1100-1500 the Middle English period where the natives did resist the Anglo-Saxon influx, the literary creations were also coming to forefront as well.

While in 1355 English was promoted as the court language the renaissance did pave way for the rediscovery of Latin and Greek classics thus influencing also the spoken language. From 1500 Latin started influencing more and the age of Modern English came to be. It is true also that "Whenever they were unable to find an apt English word for anything, they did not hesitate to seek words from Asian, South American or African languages"(Rao 288). 
English as a language was the result of the social situation and it is the reflection of man's capability to adapt and respond to the needs of the time. Only from these practices were we able to identify systems like grammar and structure. And now we shall look at the systems, which by now are the crust of English as a language here in India at least.

\section{Two systems of Teaching English}

In order to comprehend better the nuances of English education we need to keep in mind that in India there are two major types of educative systems. While we cannot forget those international syllabuses which run along in some specialized schools there are two systems of systems which provide the umbrella framework for the educative arena in India today. They are the central Syllabuses and state syllabuses. Every state in India has its own freedom of operation as of now to provide the educative system for its own citizens. And Indian educative panorama provides at least two Central Syllabuses, CBSE and ICSE. While there are other possibilities, we shall concentrate on these two systems. In all these educative situations English becomes either a means or a goal or even both.

To explicate it:

a) English is used as a goal. In all the schools, both the central and state syllabus schools in India, they do have English as one of the main languages to be taught at school. It is a subject to be learnt. In this the grammar, pronunciation, literature etc. are taught. It is here the real core of the language is dealt with. Teaching a language with its literature becomes a goal in itself.

b) English is used in English medium schools as a means. Here all subjects except the languages are taught through English and this enables students to use English as a medium of operation. The technical terms and equations here obtain a global reach as higher studies to follow will mostly be done through English.

In addition to these two systems, there is also the possibility of English being used as common language of communication. There are schools where English is used as the language of communication. There are also schools, even English medium schools where that is not the case. Especially in cases where schools having both English and vernacular medium class rooms such a possibility is a far-fetched dream.

In most of the cases there is also an ad extra factor which influences there daily language usages. Whichever may be the common language for the user, in India, English gets inserted as words and phrases with the same grammatical structure of the language being used. The influence of the global media has played a major role in this regard.

\section{English in School Education}

The actual scenario of the school education with regard to English is to be befriended and care-fronted. This is because there are clear syllabuses for the teaching of English in these systems and because there are very many other facts which influence the students and teachers with regard to their learning. What we need to care-front is the rationale behind the teaching of English in Schools. While considering the rationale we can also find out how far the actual situation responds to the rationale and how far the system has been successful in putting into practice the same logic through the various action plans. We shall point out a few factors which do play a major role in this new configuration of language uses.

\section{Connectivity}

English de facto has become a connective language, especially in pluri-lingual countries like India. Strange but true, is the fact that India with so many official languages and its multiple variations still need English to be the unifying agent. Probably thanks to the colonization and now with the neo-colonization, pet named as globalization, we are into a new euphoria of connectivity across the globe. We cannot play 
soft on the tussle between English, French and Chinese for the global domineering language position so that through language a culture can be imposed, knowingly or not, willingly, definitely yes. As for now English seems to have the upper hand. "By accidents of history [...] and by something like an explosion in the speed and ease of travel and by all factors which have broken down frontiers and forced nations into closer interdependence, English has become a world language. It is the means of international communication: there is no other" (Sachdeva 28).

English is a connective language in all post Anglican empire hemisphere and for most part, it is the language also of the internet connectivity. AS far as the Indian scenario is concerned English does play that role of connectivity. R. S. Trivedi seems to have clarified this position better. "India's connection with the Common Wealth, the UNO and its agencies, her needs of foreign trade and economic aid from different countries, her need for the technical know-how for her development and her role in the affairs of the world, all conjointly enjoin upon the framers of her educational policy to give due weight to English so that her interests do not suffer and she does not detract from her rightful place in the world policy" (Sachdeva 27).

This connectivity is reflected not only in transportation and travel but also in the global trade administration and economy. Industry and commerce and newer forms of research etc. have the same unifying agent in English. In schools and universities, English is taught as a link language so that those come out of the curriculum may find themselves at ease to communicate to the world around.

Students who frequently converse in English find themselves often in an advantageous position not only among the peers but also in the leadership scenario as those who can communicate globally become the centre of attention and orientation. That is why in most of the schools where English is the medium of communication there is a rise in the standard of educative results and mediatic mileage.

\section{Structures}

It is often true that the school tutoring of English fall under the strict regime of the structures: structures at multiple levels. There are structures of the school governance, structures of character formation and not insignificantly structures of languages.

As most students will be learning more than one language, they will be dealing with multiple linguistic structures and not always these are pleasantries. The regime of the school administration can and might provide either pleasure or pain in the learning process as well.

While the concentration on structures, and to my opinion a necessary component of learning, is needed and children learn to cop up with multiple systems to follow, there is the advantage of children learning the correct usage of languages and codes of behavior. They learn to live within the typical systems already in moto.

With regard to language it is here that they not only learn the right usage but also they become capable of analysis, comparison and composition. The creative genius works and newer literary products emerge thus taking forward the growth of the language and literature. It is only through the knowledge of those literary systems can they either follow or choose a different path when it comes to production.

\section{Literature}

While the connective forum remains one of the greatest advantages of this language, there is also a mighty repository of treasure waiting to be unveiled, used and shared within the linguistic tradition of the English language. While teaching English in schools, there is a sharing of the world literature, written originally in English or translated into English which is being made available for the global consumption. As literature falls under the cultural heritage of civilization, the magnificent horizon of literature brightens 
up for the English user. The reflection of which is seen in the scholastic curriculum as there are poems, drams and criticism from literary giants of from all the parts of the world, stipulated to be scrutinized and appreciated.

Through the literature also a culture is being transmitted into the learner. A culture with its lights and shades influence also the reader who in turn would produce his own literature with cultural connotations heavily weighing down on it. Even Mahatma Gandhi had this well appreciated while he commented: "It (English) is the language of diplomacy and it contains many a rich literary treasure; it gives us an introduction to western thought and culture"(Sachdeva 28). At this point English becomes also a library language.

And in this sphere we can very well call English as a window into the world, through which we see the horizon and through which the residue of cultures wing into our life. The cultural and counter cultural imprints fall into our society through this medium of language. The mutual influence vivid in the postmodern and globalized world panorama, English with its cultural and vernacular slags and shades do provide the rise and fall also of counter cultural and separatist movements as well, which again are only parts of the cultural progress, seen in a second analysis.

This is all true if English is dealt with a decorum it deserves. While the ideal might assume this picture there is also another corner of challenge which seems to undermine every progressive intervention. In most of the schools of the vernacular medium teachers need not be fluent in the English parlance as they never had such opportunities for the same. Theoretically the degree passed with sufficient marks could make one a teacher while the personal quality in the usage of the language need not arise to required levels for a fluent conversation.

The lack of efficient teachers and adequate teaching aids, added with a clear lack of purpose accompanied by faulty methods can bring down on to the knees every aspiring English speaker. This would endanger also the cultural exchange through the original language leaving it to the mercy of the vernacular. The scientific ardor in teaching and learning mounted with the cultural impact provided by the global media twist the scenario into something clearly new and aggressive; a counter tendency to provide alternative communication system for the often informal set ups.

This is where we need to verify how far the English tutoring in schools do influence the social communication of the younger generations. We will not go any further in the analysis of the scholastic system for the moment as it might require a much larger platform for discussion. Yet, facts are here for us to verify.

\section{Counter linguistic culture}

So far we have seen how school education has promoted English as a global language. It is time now to verify if those elements which we thought to be essential, especially the linguistic structure and literary heritage still play vital in the communicative systems of the contemporary children, especially in their informal world, call it the social media. The chat messages and the social media logic often would raise eye brows as they see to be counterproductive and destructive with regard to the original classical English learning. We shall take only a few examples from the world of youth social communication to pin down a few conclusions. 


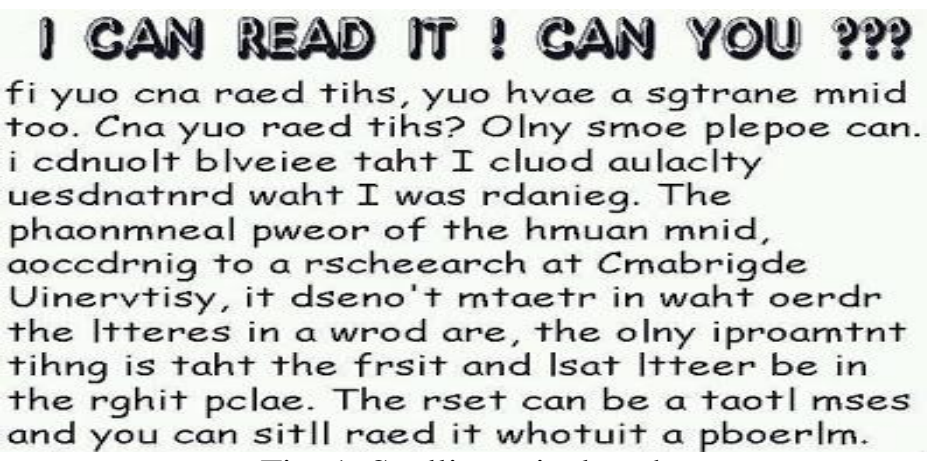

Fig. 1. Spelling misplaced.

This is the first of our considerations. Here what is proved is that the reader has a mind which simply tells that the spelling need not be accurate in order to communicate. In fact the differences in spelling between the American and English variations of English actually do not make us bother too much. Take the example of the word 'Colour' and 'Color'.

But the common factor is that in most places almost all letters are present. And that reminds us that this sort of writing is not new, but old and yet effective. Here the order of placing letters has been altered yet the content seems to be readable and hence comprehensible. We do not want to enter into discussions on the power of mind to order and converge etc.

We shall take another example. In this second example I have moved for an experiment.

I gave a few lines to the youth and asked them to text me the same through any one of the social media channels. Here I bring along the original text.

- $\quad$ Can you please let me see the picture? It is really awesome. I like it. My daddy and mummy are not at home; so I cannot really come out for the party tonight. Good night. Sweet Dreams.

And here are a few responses I have chosen from the many.

1) Can U pls let me see the pic? It's really ozzm. I like it. Ma dad n Mum r nt @ hom; so, I cnt realy com out 4 the party tonit. Gud nyt, SD

2) Cn U plz lt me C d pic? Its rly Awsm. I lyk it. My dad n mom r nt @ hm; so I cnt rly com out 4 d parti 2 n8. Swt dmz.

3) Dud lt me C d pic. Awzm yar. Ma dadnmumnt@ @om nt $b$ thr 4 d prty. Gd n8. Swt Drmz.

Those who responded belonged to different categories.

- Those who responded did not really care if they had a scientific training in writing English or not.

- They belonged to the category of English Medium and Malayalam Medium students and it did not matter to them at all.

- They came from four different districts of Kerala and there was not much of a difference in the modality of responses. 
- Those who responded had rich, poor and middle class backgrounds, yet with regard to the responses, it did not matter.

While that being the condition of those who responded, there are a few conclusions which I would like to retrieve.

- First of all, they use symbols to communicate and not always words. Example: '@ ', '\&' etc.

- There is a tendency to omit the vowels wherever it is possible. Example: 'tht', 'swt' etc.

- There are no specific patterns for all communications. It differs from persons. Example: 'Pls' and 'Plz'; 'Nit' and 'Nyt'.

- There are also common trends in their writing. Example: 'Swt', 'pic' etc.

- Spelling and grammar are not the main issues here.

- Provided the message is communicated, the effort has been successful.

- Perfection is not the pattern but usefulness.

- Adjustments are the mode of the way.

If this is the analysis then there are a few primary questions to be asked to those who learn and teach English as a language and as Literature.

- Did all the pain and trouble in teaching a structure really serve in the long run?

- Is it worth spending such an amount of energy for teaching classic English while in the actuality the youth of today deviate from that?

- Are the counter linguistic signs that we read from the social media signs that the strict regime is considered with aversion by the younger generations?

- And worse still: Can there be a point of convergence between the generations, if the younger ones vehemently deviate from that which is called real, original and the most correct?

\section{Conclusion}

We have seen right from the beginning the effort which is laid in order to teach good and correct English to the students from the school days. We have seen also the advantages of English as a global language. We have really understood that the youth of today have a different modus pensanti that they are capable of filtering the rigid and taking in only the apparently more useful. But it is important to note also that the primary aim of a language that of communication and connectivity is obtained even through the current style of writing. Moreover, with the insertion smileys and emoticones the communication goes beyond the parameters of English itself, for that matter of any language.

So probably it is time to pause to realize that the world is moving into a more global language, a more semiotically novel affair so that the linguistic barriers are demolished. But we can still think that newer boundaries are created while the old is toppled. The internet savvy youth of today may not really fall obedient to any controlling mode of operation. Because here "Social norms are challenged since socially erected control systems may not be operating in this new set up" (Varghese 31). As the psychology of the youth demands, the more a controlling procedure is followed there is a greater tendency in the youth to fall away from all such initiatives. There are clear signs of counter culture and counter linguistic trends while there are also signs of linguistic convergence. After all every language progressed through the convergences of ideas and vocabulary, this time also the symbols for writing a message too.

Every language is a complex set of signs. Language is written, if it consists of signs written on a surface. It is spoken when it is carried out orally with pronounced words. It is ideagraphic if symbols express ideas, just like the Chinese language where eyes represent vision and ear represent hearing. Language can be phonetic or phonographic if particular signs are given particular meanings and these signs are made use of in communication as language, just as in the case of short hands and codes (Maurus 59-60). 
Staying within these parameters of language, what the new media uses is nothing but a language. It is the point of convergence beyond the boundaries of traditional languages. Whatever be the source language there emerges a new form, often manipulated and phonetically based system which tends to communicate faster and farther. Apart from the colloquial and social forum discussions, can these create solid literature found so standing within the parameters of the traditional concept? Only time can answer it.

But the fact remains, the social media youth users have taken seriously the main function of the language, that of being an instrument of communication and have given lesser importance to the structure of the language. It is right there that the points of a counter tendency as that of convergence are seen concretely. With regard to the literary contribution through these language modalities, it is for the time to evaluate.

\section{References}

1) Franz-Josef Eilers. Communicare nella Communita', Editrice Elle Di Ci, Torino, 1994. Print.

2) Maurus J. The Art of Communicating Effectively, Better yourself Books, Bandra, 2005. Print.

3) Sachdeva M.S. A New Approach to Teaching of English in India, Tandom Publications, Ludhiana, 2008. Print.

4) Varghese C.P., Cyber Psychology and Youth, Bosco Institute of Social Sciences, Bangalore, 2013. Print.

5) Rao Madhukar, A Literary Salad, Prism Books, Kochi, 2014. 285-289. Print. 